\title{
Produção de minitubérculos básicos de batata em três sistemas hidropônicos
}

\author{
Thiago L Factor; Jairo AC de Araujo; Felipe PC Kawakami; Viviane Iunck

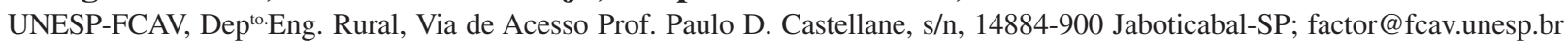

\section{RESUMO}

O presente trabalho teve como objetivo avaliar a produção de minitubérculos básicos de batata em três sistemas hidropônicos de cultivo: aeropônico, DFT (deep flow technique) e NFT (nutrient film technique). $\mathrm{O}$ experimento foi realizado em ambiente protegido, de maio a setembro de 2005, em Jaboticabal, SP. Adotou-se o delineamento experimental em blocos casualizados com parcelas subdivididas, sendo os três sistemas hidropônicos de cultivo as parcelas principais e, as cultivares Agata e Monalisa, as subparcelas. A massa fresca e o diâmetro longitudinal dos tubérculos não foram influenciados pelos sistemas hidropônicos estudados, com valores médios de 6,2 e $30,2 \mathrm{~mm}, 6,3 \mathrm{~g}$ e $30,0 \mathrm{~mm}, 6,8 \mathrm{~g}$ e $31,0 \mathrm{~mm}$, para os sistemas hidropônicos NFT, DFT e aeroponia, respectivamente. No que se refere às cultivares, Monalisa apresentou maior diâmetro longitudinal e massa fresca $(32,2 \mathrm{~mm}$ e $7,1 \mathrm{~g})$, valores significativamente superiores aos verificados para a cultivar Agata $(28,6 \mathrm{~mm}$ e $5,8 \mathrm{~g})$. $\mathrm{O}$ número de minitubérculos por planta e por metro quadrado teve valores médios significativamente superiores no sistema aeropônico $(49,3$ e 874,4$)$ em relação aos sistemas NFT $(39,5$ e 246,6$)$ e DFT (41,6 e 458,0), respectivamente. A produção de minitubérculos básicos de batata pode ser realizada de maneira eficiente utilizando-se os sistemas hidropônicos estudados, sendo o sistema aeropônico o que apresentou os melhores resultados.

Palavras-chave: Solanum tuberosum, aeroponia, DFT, NFT, cultivo sem solo, colheita escalonada.

\section{ABSTRACT}

Potato basic minitubers production in three hydroponic systems

The objective of this work was to evaluate the production of potato basic minitubers in three hydroponic systems: aeroponic, DFT (deep flow technique) and NFT (nutrient film technique), using cultivars Agata and Monalisa. The experiment was carried out under protected cultivation, from May to September, 2005, in Jaboticabal, São Paulo State, Brazil, in a completely randomized block design, with split-plots. The hydroponic systems were assigned to the experimental plots, whereas cultivars were assigned to sub-plots. Tuber fresh weight and longitudinal diameter were not influenced by the hydroponic systems, with average values of $6,2 \mathrm{~g}$ and 30,2 $\mathrm{mm}, 6,3 \mathrm{~g}$ and $30,0 \mathrm{~mm}, 6,8 \mathrm{~g}$ and $31,0 \mathrm{~mm}$, for hydroponic systems NFT, DFT and aeroponic, respectively. Between cultivars, Monalisa presented larger longitudinal diameter and fresh mass $(32,2 \mathrm{~mm}$ and $7,1 \mathrm{~g})$, significantly superior when compared to Agata $(28,6 \mathrm{~mm}$ and $5,8 \mathrm{~g}$ ). Minituber yield per plant and $\mathrm{m}^{2}$ was significantly higher in the aeroponic system $(49,3$ e 874,4$)$ in comparison the NFT $(39,5$ e 246,6) and DFT systems (41,6 e 458,0), respectively. Results indicate that basic potato minitubers can be efficiently produced using the hydroponic systems evaluated in this work. Among them, the aeroponic system presented the best results.

Keywords: Solanum tuberosum, aeroponycs, DFT, NFT, soilles production, repeated harvesting.

\section{(Recebido para publicação em 19 de julho de 2006; aceito em 16 de abril de 2007)}

\begin{abstract}
A batata (Solanum tuberosum L.) soAfre intenso processo de degenerescência com significativa redução na produção, em virtude do acúmulo de agentes viróticos nos tubérculos através das sucessivas gerações de propagação vegetativa. Assim, a manutenção de uma boa produtividade requer uma regular introdução de novo material de propagação. Nesse sentido, a constante utilização de sementes de alto padrão fitossanitário é fundamental para a exploração comercial da batata e merece atenção especial por parte do produtor. Dentre outras razões, isso se faz necessário por ser também a batata-semente o componente mais alto no custo de produção (30 a 40\%) e por ter reflexos diretos na produtividade e qualidade dos tubérculos (Assis, 1999). Assim, a utilização de técnicas de cultura de
\end{abstract}

meristemas para eliminação de viroses e propagação in vitro de plantas sadias e posterior multiplicação em ambientes protegidos telados ganham cada vez mais importância na produção da batata. Todavia, essa técnica, que utiliza procedimentos laboratoriais e equipamentos específicos, ainda apresenta custos elevados e demanda mão-de-obra altamente qualificada.

O sucesso da limpeza clonal depende, portanto, de sistemas eficientes de multiplicação do material livre de fitopatógenos, de maneira a viabilizar o processo inicial de produção de batatasemente. Ademais, os métodos tradicionais de produção de tubérculos-semente, em matriz sólida, normalmente solo ou substrato, apresentam como característica comum uma baixa eficiência produtiva. Segundo Daniels et al. (2000), são produzidos em média de três a cinco tubérculos por planta, o que contribui sobremaneira para elevar ainda mais os custos de produção da batata-semente.

Dentre os métodos empregados em vários países como forma de substituir os métodos convencionais de produção de tubérculos-sementes em solo ou substratos destacam-se os sistemas hidropônicos (Wheeler et al., 1990; Wan et al., 1994; Muro et al., 1997; Rolot \& Seutin, 1999; Ritter et al. 2001; Rolot et al. 2002). Nesses sistemas, por não haver contato dos tubérculos-sementes com fitopatógenos de solo, facilidade de limpeza após ciclo de produção, melhor controle sobre os fatores que interferem na nutrição das plantas e principalmente devido à possibilidade de se fazer uma colheita escalonada, a produção de minitubérculos apresenta excelente pa- 
dronização, alta qualidade fitossanitária e maior taxa de multiplicação.

No Brasil, os resultados até então alcançados com a produção de minitubérculos em sistemas hidropônicos têm apontado um importante avanço na produção de sementes pré-básicas de batata. Na região sul do País, Pereira et al. (2001), citado por Medeiros et al. (2002), obtiveram valores de 32,4 e 23,0 minitubérculos plan$\mathrm{ta}^{-1}$, trabalhando com mudas provenientes da cultura de meristemas e utilizando o sistema de calha articulada (NFT) e colheita escalonada para as cultivares Baronesa e Elisa, respectivamente. A introdução de novos sistemas de produção de sementes pré-básicas que propiciem maiores taxas de multiplicação de material derivado da propagação in vitro trará significativos avanços na cadeia produtiva da batata, capaz de produzir reflexos positivos na produtividade, particularmente em regiões onde a qualidade das sementes utilizadas é fator limitante para a obtenção de maiores rendimentos (Medeiros et al., 2002).

Diante do exposto o objetivo deste trabalho foi avaliar a produção de minitubérculos de batata-semente básica em três sistemas hidropônicos de cultivo: aeropônico, DFT (deep flow technique) e NFT (nutrient film technique).

\section{MATERIAL E MÉTODOS}

O experimento foi realizado de maio a setembro de 2005, na UNESP em Jaboticabal (21ำ15'15" S, 48¹8'09" W, altitude média de $595 \mathrm{~m})$. O ambiente protegido utilizado foi do tipo capela não-climatizada, com orientação LesteOeste, inclinação da cobertura de $22^{\circ} \mathrm{em}$ relação à horizontal, construída em estrutura metálica (ferro galvanizado), possuindo dimensões 10x10 m e altura do pé direito de 4,0 m. Na cobertura da estrutura foi utilizado polietileno de baixa densidade (PEBD) transparente com espessura de $0,15 \mathrm{~mm}$ e, nas laterais, tela antiafídeos branca, da superfície do solo à extremidade do plástico de cobertura.

As cultivares estudadas foram Agata e Monalisa. Utilizaram-se plântulas oriundas de micropropagação, formadas em bandejas de espuma fenólica de 54 células $(5 \times 5 \times 3,8 \mathrm{~cm})$, com aproximadamente $12 \mathrm{~cm}$ de altura e cinco folhas por ocasião do transplantio, ocorrido em $18 / 05 / 05$.

A solução nutritiva utilizada foi a mesma para os três sistemas hidropônicos estudados, adaptada de Medeiros et al. (2002) e Rolot et al. (2002), com a seguinte concentração de nutrientes $\left(\mathrm{mg} \mathrm{L}^{-1}\right)$ : $145 \mathrm{de} \mathrm{NO}^{-}, 29 \mathrm{de}$ $\mathrm{NH}_{4}^{+}, 40$ de $\mathrm{P}, 295$ de K, 162 de $\mathrm{Ca}, 40$ de $\mathrm{Mg}, 64$ de S, 2,0 de Fe, 0,3 de Zn, 1,0 de $\mathrm{Mn}, 0,3$ de B, 0,05 de $\mathrm{Cu}$ e 0,05 de Mo. A solução nutritiva foi colocada em reservatórios de $1000 \mathrm{~L}$, um para cada sistema hidropônico, localizado a $7 \mathrm{~m}$ do ambiente protegido. Acoplado ao reservatório um conjunto moto-bomba elétrico, regulador de pressão e filtro de tela de 100 mesh. Os três sistemas hidropônicos são do tipo fechado, ou seja, a solução nutritiva retorna por gravidade, por meio da tubulação de drenagem, para o reservatório de armazenamento. O manejo da solução nutritiva constou da reposição diária da quantidade de água consumida pelas plantas e perdida por evaporação, bem como a correção do $\mathrm{pH}$ e condutividade elétrica (CE) da solução nutritiva, conforme a necessidade de ajuste. $\mathrm{O} \mathrm{pH}$ foi mantido entre 5,5 a 6,0 e, a CE, entre 1,8 e $2,3 \mathrm{mS} \mathrm{cm}^{-1}$, por meio da adição de ácido ou base e solução estoque concentrada.

Foram realizadas colheitas semanais, adotando o critério de colher os tubérculos tão logo atingissem o diâmetro desejado, classificado como tipo V (16 a 23 $\mathrm{mm}$ ) (Embrapa, 2000), conforme sugerido por Medeiros (2003) e Relloso et al. (2000). Foram analisadas as características massa fresca média e diâmetro longitudinal dos tubérculos e número de tubérculos por planta e por $\mathrm{m}^{2}$.

$\mathrm{O}$ delineamento experimental utilizado foi blocos casualizados com parcelas subdivididas, sendo os três sistemas de cultivo hidropônico (NFT, DFT e aeroponia) distribuídos nas parcelas e, as cultivares Agata e Monalisa, nas subparcelas. Foram analisadas 5; $10 \mathrm{e}$ 18 plantas em cada subparcela nos sistemas hidropônicos NFT, DFT e aeroponia, respectivamente. Cada bloco continha duas repetições de cada sistema, em um total de quatro blocos.
Analisaram-se os dados pelo programa estatístico SAS, utilizando-se o teste Tukey a 5\% de probabilidade para a comparação das médias. As interações, quando significativas, foram estudadas através de análise de regressão.

Os sistemas hidropônicos utilizados apresentaram as seguintes características básicas:

\section{Sistema hidropônico DFT (Deep Flow Technique)}

Esse sistema baseou-se na interpolação de duas canaletas de fibrocimento trapezoidais, com dimensões de 0,18 m, 0,40 m e 0,20 m, para a base menor, base maior e altura, respectivamente; e comprimento de $2 \mathrm{~m}$, recobertas por um filme de polietileno preto e sustentadas por uma estrutura metálica de $1 \mathrm{~m}$ de altura mantida no nível, sem declividade. No interior destas canaletas foi colocado um suporte (tela) metálica com malha de 2 polegadas a $8 \mathrm{~cm}$ de altura, sob o qual foi fixado uma tela de polipropileno preto $(30 \%)$, de maneira a permitir que o sistema radicular atingisse a camada de solução nutritiva $(6 \mathrm{~cm}$ limitada pelo sistema de drenagem), mas não a maioria dos estolões, formando uma zona de tuberização (Figura 1). No espaço entre a tela e a lâmina de solução nutritiva, forma-se uma camada de ar de aproximadamente $2 \mathrm{~cm}$, responsável por auxiliar na respiração das raízes. De maneira a evitar a entrada de luz no sistema radicular das plantas foi colocado um filme de polietileno com a cor branca para cima e preta para baixo, sobre as canaletas de cultivo. Posteriormente as plantas foram transplantas em orifícios abertos na forma de cruz neste filme plástico, no espaçamento de $0,15 \times 0,15$ m. Para a condução das plantas foram fixadas duas chapas de ferro fundido $(20 \times 5 \mathrm{~mm})$ nas extremidades das canaletas de cultivo e, à medida em que as plantas se desenvolviam, foram estendidos arames ( $\mathrm{n}^{\mathrm{o}}$ 14) por toda a linha de cultivo e no intervalo de $10 \mathrm{~cm}$, de maneira a evitar o acamamento das mesmas.

\section{Aeroponia}

Neste sistema as plantas se desenvolveram em uma câmara (caixa) de fibra-de-vidro, com dimensões de 2,0 m de comprimento, 0,5 $\mathrm{m}$ de largura, 0,6 
Tabela 1. Massa fresca, diâmetro longitudinal e rendimento de minitubérculos por planta e por $\mathrm{m}^{2}$, cultivares Agata e Monalisa, em sistemas hidropônicos NFT, DFT e Aeroponia. (Minituber fresh weight, longitudinal diameter, and yield per plant and per $\mathrm{m}^{2}$, cultivars Agata and Monalisa, in NFT, DFT, and aeroponic hydroponic systems). Jaboticabal, UNESP, 2005.

\begin{tabular}{|c|c|c|c|c|}
\hline Tratamentos & $\begin{array}{c}\text { Massa } \\
\text { fresca }(g)\end{array}$ & $\begin{array}{c}\text { Diâmetro } \\
\text { longitudinal } \\
(\mathrm{mm})\end{array}$ & $\begin{array}{l}\text { Número } \\
\text { tubérculos } \\
\text { (planta) }\end{array}$ & $\begin{array}{c}\text { Número } \\
\text { tubérculos }\left(m^{2}\right)\end{array}$ \\
\hline \multicolumn{5}{|c|}{ Sistemas de Cultivo (SC) } \\
\hline NFT & $6,2 \pm 0,3 A^{1}$ & $30,2 \pm 0,7 \mathrm{~A}$ & $39,5 \pm 1,1 \mathrm{~B}$ & $246,6 \pm 7,1 \mathrm{C}$ \\
\hline DFT & $6,3 \pm 0,2 \mathrm{~A}$ & $30,0 \pm 0,6 \mathrm{~A}$ & $41,6 \pm 1,5 \mathrm{~B}$ & $458,0 \pm 16,7 B$ \\
\hline Aeroponia & $6,8 \pm 0,2 \mathrm{~A}$ & $31,0 \pm 0,5 \mathrm{~A}$ & $49,3 \pm 1,1 \mathrm{~A}$ & $874,4 \pm 9,5 \mathrm{~A}$ \\
\hline C.V. (\%) & 12,6 & 4,77 & 5,9 & 6,0 \\
\hline DMS (5\%) & 0,8 & 1,34 & 2,4 & 29,4 \\
\hline \multicolumn{5}{|l|}{ Cultivares (CV) } \\
\hline Agata & $5,8 \pm 0,1 \mathrm{~B}$ & $28,6 \pm 0,2 B$ & $40,3 \pm 1,3 \mathrm{~B}$ & $492,1 \pm 53,9 B$ \\
\hline Monalisa & $7,1 \pm 0,2 \mathrm{~A}$ & $32,2 \pm 0,4 \mathrm{~A}$ & $46,6 \pm 1,1 \mathrm{~A}$ & $560,1 \pm 56,7 \mathrm{~A}$ \\
\hline C.V. $(\%)$ & 10,5 & 5,2 & 11,2 & 12,0 \\
\hline DMS (5\%) & 0,4 & 1,0 & 2,9 & 37,8 \\
\hline Teste F p/ SC & $2,2 \mathrm{~ns}$ & $2,1 \mathrm{~ns}$ & $66,6^{* *}$ & $1615,4^{* *}$ \\
\hline Teste F p/ CV & $41,1^{* *}$ & $58,3^{* *}$ & $20,2^{* *}$ & $13,8^{* *}$ \\
\hline Teste F p/ Int. SC x CV & $0,1 \mathrm{~ns}$ & $0,8 \mathrm{~ns}$ & $0,4 \mathrm{~ns}$ & $0,3 \mathrm{~ns}$ \\
\hline
\end{tabular}

${ }^{1}$ Médias seguidas da mesma letra nas colunas não diferem entre si pelo teste de Tukey, $\mathrm{p}<$ 0,05 (Means followed by the same letter in the column do not differ from each other, Tukey's test, $\mathrm{p}<0,05)$.

$\mathrm{m}$ de altura e de 3 a $5 \mathrm{~mm}$ de espessura de parede. A solução nutritiva foi nebulizada (alta pressão e baixa vazão) diretamente no sistema radicular, que se desenvolveu dentro da caixa e no ar (Figura 2). Foram colocados três nebulizadores (NAADANNâ, modelo Fogger, com vazão de $14 \mathrm{~L} \mathrm{~h}^{-1}$ a 4 atm) em cada uma das quatro linhas laterais de cada caixa (168 L). Na tampa das caixas foram feitos orifícios de $0,05 \times 0,05 \mathrm{~m}$, com espaçamento entre plantas de $0,15 \times 0,15 \mathrm{~m}$, à semelhança do sistema DFT. Apoiados a estes orifícios foram construídas pequenas estruturas metálicas de 0,05 m de largura e 0,10 $\mathrm{m}$ de altura, de maneira a acondicionar e promover suporte para as plântulas. No tutoramento das plantas foram utilizadas fios de arame $\left(\mathrm{n}^{\circ} 14\right)$ fixados nas extremidades por meio de cantoneiras de ferro fundido de 3/4" e dispostos paralelamente às caixas em intervalos de $10 \mathrm{~cm}$. A colheita dos minitubérculos foi feita através de janelas laterais construídas para tal finalidade. O tempo de nebulização foi modificado em função do ciclo e necessidades fisiológicas das plantas, monitoradas pela observação visual do estado de turgescência e por meio de um temporizador eletrônico conectado a um microcomputador. tar a entrada de luz no sistema radicular das plantas, que prejudicaria a emissão de estolões e tubérculos, foi fixado um filme de polietileno preto, com $0,4 \mathrm{~m}$ de largura e $2 \mathrm{~m}$ de comprimento, ao longo de toda a borda da calha superior, envolvendo posteriormente a calha inferior e prendendo-o na borda externa daquela calha. Para a condução das plantas foram fixados sarrafos de madeira de $(50 \times 20 \mathrm{~mm})$ nas extremidades dos canais de cultivo, estendendo-se posteriormente arames $\left(n^{\circ} 14\right)$ por toda a linha de cultivo, à semelhança dos sistemas descritos anteriormente.

\section{RESULTADOS E DISCUSSÃO}

Para a massa fresca e diâmetro longitudinal dos tubérculos, verificou-se que não houve efeito significativo entre sistemas de cultivo e tampouco da interação entre sistemas de cultivo e cultivares (Tabela 1), sendo possível verificar diferenças significativas apenas entre cultivares. Os tubérculos da cultivar Monalisa apresentaram maior diâmetro longitudinal e massa fresca (32,2 mm e 7,1 g), valores significativamente superiores aos verificados para a cultivar Agata (28,6 mm e 5,8 g) Maior massa fresca e comprimento médio dos tubérculos da cultivar Monalisa em relação à cultivar Agata também foi verificado por Corrêa et al. (2004), porém em sistema de canteiros suspensos contendo substrato orgânico e em colheita única. Em colheita escalonada, utilizando o mesmo sistema, não se obteve diferenças significativas entre as cultivares. Vermeer (1990) ressalta que existe uma resposta genotípica diferencial de cultivares de batata quanto ao tamanho e forma dos tubérculos, independentemente das condições de cultivo. De maneira geral, para os três sistemas hidropônicos de cultivo, os valores da massa fresca dos minitubérculos variaram de 6,2 a $6,8 \mathrm{~g}$, portanto, na faixa adequada de peso de colheita para minitubérculos (Medeiros, 2003).

Em relação ao número de minitubérculos planta ${ }^{-1}$ ao longo das sucessivas colheitas, verificou-se que nos três sistemas de cultivo estudados os valores assumiram uma tendência polinomial, ajustando-se ao modelo 
quadrático de regressão (Figura 3). O sistema aeropônico proporcionou a produção de um maior número de minitubérculos planta $^{-1}$ durante todo o período experimental. Os sistemas DFT e NFT apresentaram valores semelhantes entre si (Tabela 1).

A maior taxa de multiplicação de tubérculos ocorreu 72, 73 e 74 dias após o transplantio (DAT), período compreendido entre a $6^{\text {a. }}$ e $7^{\text {a. }}$ colheitas, com valores da ordem de 5,3; 5,6 e 6,0 minitubérculos planta $^{-1}$, respectivamente, para os sistemas NFT, DFT e aeroponia. Resultados semelhantes foram encontrados por Relloso et al. (2000), que obtiveram maior taxa de multiplicação por volta da $6^{\mathrm{a}}$ colheita, porém diferentes do constatado por Medeiros (2003), que obteve pico de produção se por volta da $4^{\mathrm{a}}$ colheita.

Quanto ao número médio de minitubérculos por planta, obtido ao final do experimento, foram verificadas diferenças significativas entre sistemas hidropônicos e cultivares. No entanto, não se observou efeito significativo da interação entre os dois fatores. A comparação entre os três sistemas hidropônicos de cultivo mostrou um número médio de minitubérculos significativamente superior $(49,3)$ no sistema aeropônico em relação aos sistemas NFT $(39,4)$ e DFT $(41,6)$, que não diferiram entre si (Tabela 1). No tocante às cultivares, verificou-se que a cultivar Monalisa apresentou número estatisticamente superior de minitubérculos planta $^{-1}(46,6)$ quando comparada à cultivar Agata $(40,3)$.

No sistema aeropônico, por não haver nenhum tipo de impedimento ao desenvolvimento do sistema radicular das plantas, é possível que a emissão de novas raízes e estolões seja facilitada, contribuindo sobremaneira para aumento no número de minitubérculos planta ${ }^{-1}$. Vreugdenhil \& Struik (1989) mencionam que estolões de batata produzem etileno quando encontram resistência mecânica ao crescimento e, como resultado, o desenvolvimento do estolão é cessado, sendo necessário que, nesta ocasião, as concentrações de giberelina sejam insuficientemente baixas para promover a tuberização. Lugt et al. (1964) reportam um crescimento extre-

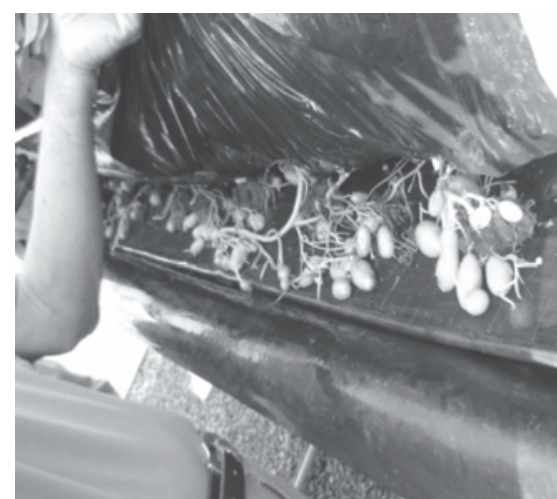

Figura 1. Colheita sobre a tela, sistema DFT, 32 dias após o transplante, cultivar Monalisa (Harvest over screen, DFT system, 32 days after transplanting, cultivar Monalisa). Jaboticabal, UNESP, 2005.

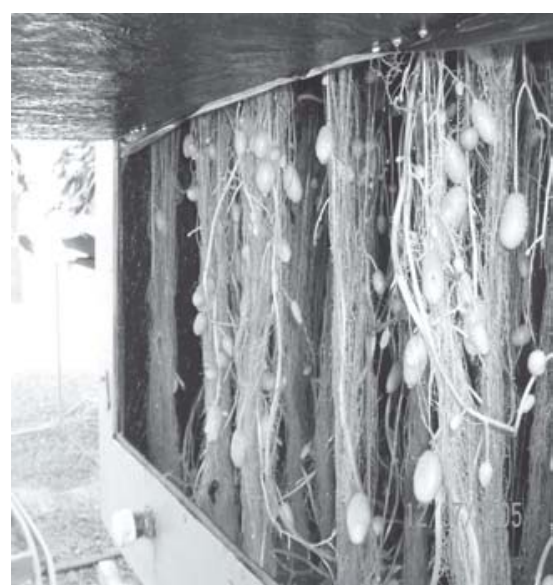

Figura 2. Janelas laterais que facilitam a colheita escalonada, sistema aeropônico, 54 DAT, cultivar Ágata (Lateral windows which help the repeated harvesting, aeroponic system, cultivar Agata). Jaboticabal, UNESP, 2005.

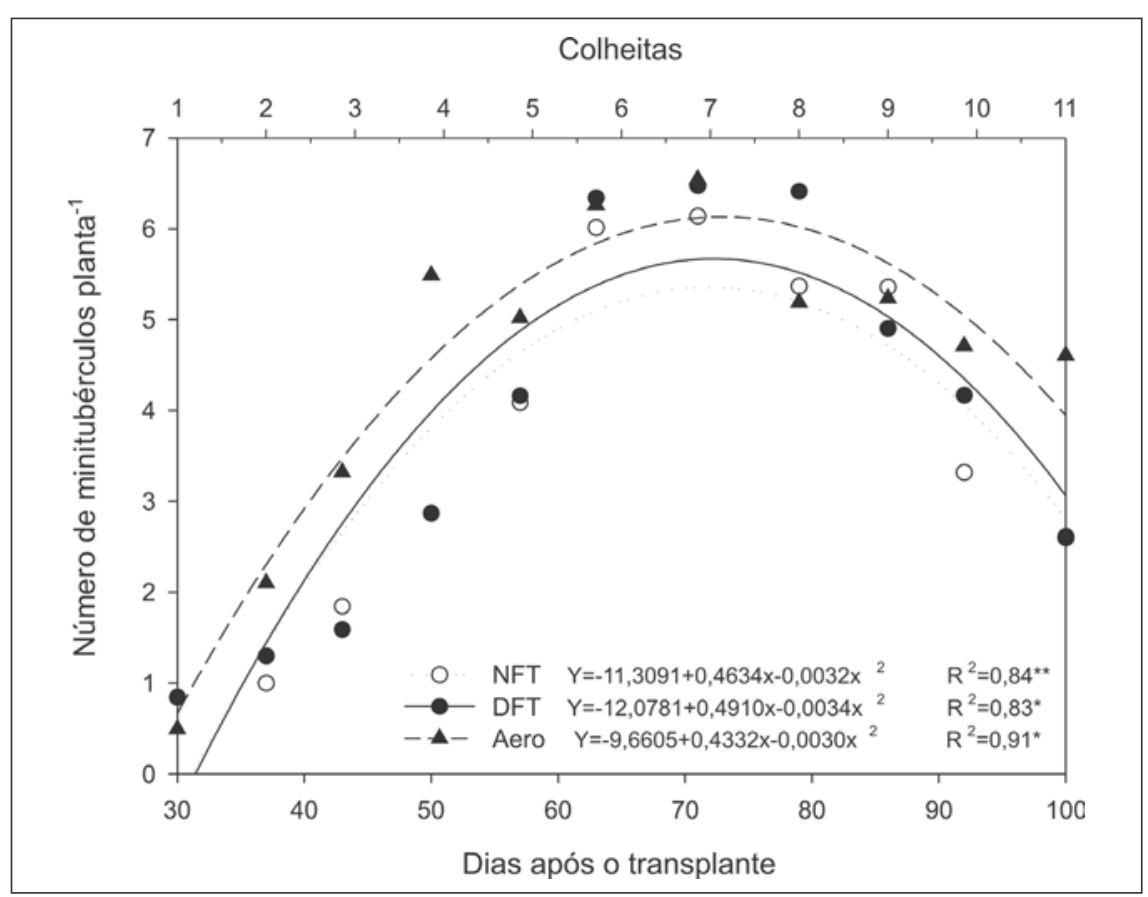

Figura 3. Número de minitubérculos planta ${ }^{-1}$ para os sistemas hidropônicos NFT, DFT e aeroponia, em onze colheitas. (Minituber yield plant ${ }^{-1}$ for NFT, DFT, and aeroponic hydroponic systems, in eleven harvests). Jaboticabal, UNESP, 2005.

mamente vigoroso de estolões e atraso na tuberização quando o sistema radicular se desenvolve em um ambiente sem resistência mecânica ao crescimento. Comportamento semelhante foi observado nesta pesquisa, em que o sistema aeropônico favoreceu o crescimento livre dos estolões e um pequeno atraso na tuberização, constatado através do menor número de tubérculos obtidos na $1^{\text {a }}$ colheita em relação aos outros siste- mas, que foi compensado nas colheitas subseqüentes (Figura 2). Gray (1973) menciona que a remoção da resistência mecânica ainda nos estágios iniciais do desenvolvimento do sistema radicular de plantas de batata induz a formação de estolões secundários e maior número de tubérculos pequenos. Além disso, Soffer \& Burger (1988) consideram a maior aeração do sistema radicular das plantas nos sistemas aeropônicos como 
um dos fatores principais no aumento da produtividade quando comparado aos sistemas hidropônicos tradicionais de produção.

À semelhança do verificado neste trabalho, embora com valores inferiores, Ritter et al. (2001) obtiveram maior taxa de multiplicação de tubérculos no sistema aeropônico $(11,6)$, quando comparado aos sistemas NFT $(5,2)$ e em substratos (tradicional) $(6,6)$, porém trabalhando com a cultivar Nagore e colhendo tubérculos com 30 a $35 \mathrm{~mm}$ de tamanho.

De maneira geral, para os três sistemas hidropônicos estudados, no que diz respeito à colheita escalonada, os resultados obtidos neste trabalho corroboram os encontrados por Medeiros et al. (2002), Medeiros (2003) e Corrêa et al. (2005), ou seja, obtém-se expressivo aumento no número de tubérculos por planta colhendo os tubérculos tão logo atinjam o tamanho desejado. Isto se deve a um estímulo à diferenciação e formação de novos tubérculos e, ainda, à economia da energia que seria normalmente utilizada para o aumento do tamanho dos tubérculos; com a eliminação dessa demanda, a energia é carreada para a formação de novos tubérculos, propiciando maiores taxas de multiplicação quando comparado aos sistemas de cultivo no solo ou substrato (Medeiros, et al., 2002). No cultivo em solo ou subtrato, há relatos de taxas de multiplicação variando de 5,0 e 7,4 minitubérculos planta ${ }^{-1}$ (Daniels et al., 2000; Andriolo et al., 2005; Favoretto, 2005).

A quantidade de minitubérculos produzidos por $\mathrm{m}^{2}$ foi substancialmente influenciada pelos sistemas hidropônicos de cultivo estudados. Foram observadas também diferenças significativas entre cultivares, porém não houve interferência significativa da interação entre sistema de cultivo e cultivar. O rendimento de minitubérculos no sistema aeropônico (874,4 minitubérculos $\mathrm{m}^{-2}$ ) foi significativamente superior ao rendimento dos demais sistemas (DFT = 458,0; NFT = 246,6), que também diferiram significativamente entre si. Uma das razões que leva a uma expressiva diferença na taxa de multiplicação por $\mathrm{m}^{2}$ entre os sistemas está no fato de que, embora adotado o mesmo espaçamento entre plantas $(15 \mathrm{~cm})$, os sistemas possuem características construtivas distintas e consequentemente acondicionam maior ou menor número de plantas por $\mathrm{m}^{2}$. O sistema NFT, por exemplo, pode conter no máximo 6,25 plantas por $\mathrm{m}^{2}$, ao passo que o DFT pode comportar 11 plantas por $\mathrm{m}^{2} \mathrm{e}$, o aeropônico, 17,7 plantas por $\mathrm{m}^{2}$, levando-se em consideração a mesma área destinada a corredores de acesso e colheita. Esta característica, própria de cada sistema, aliada ao fato de haver diferenças significativas relacionadas ao número de minitubérculos por planta entre os sistemas (Tabela 1), permite que a taxa de multiplicação do sistema aeropônico sejam tão superiores aos demais.

Os resultados obtidos permitem concluir que é possível produzir minitubérculos básicos de batata, cultivares Ágata e Monalisa, nos sistemas hidropônicos descritos, com vantagens em termos de rendimento de minitubérculos em relação ao sistema tradicional, que utiliza uma matriz sólida para ancoragem das plantas. Apesar das diferenças entre cultivares, os resultados indicaram que, entre os sistemas estudados, o sistema aeropônico foi o mais eficiente.

\section{AGRADECIMENTOS}

Os autores agradecem ao CNPq pela concessão da bolsa de estudo e auxílio financeiro e ao laboratório Biovitrus e às empresas Irrigaplan, Lauman e Nortene, pela contribuição indispensável na realização da pesquisa.

\section{REFERÊNCIAS}

ANDRIOLO JL; BISOGNIN DA; GODOI RS; BORTOLOTTO OC; COGO CM; MADALÓZ JCC. 2005. Produtividade de tubérculos semente de batata em cultivo hidropônico com dois substratos. In: CONGRESSO BRASILEIRO DE OLERICULTURA, 45. Resumos... Goiânia: SOB (CD-ROM).

ASSIS M. 1999. Novas tecnologias na propagação de batata. Informe Agropecuário 20: 30-33.

CORRÊA RM; PINTO JEBP; REIS ES; MONTEIRO AB; CHAGAS JE; RODRIGUES HCA; BERTOLUCCI SKV. 2004. Produção de batata-semente em sistema de canteiros. In: CONGRESSO BRASILEIRO DE OLERICULTURA, 44 Resumos...Campo Grande: SOB (CD-ROM).
CORRÊA RM; PINTO JEBP; PINTO CABP; FAQUIN V; REIS ES; MONTEIRO AB; SILVA FS; PINTO LBB; BERTOLUCCI SKV. 2005. Comparativo de produção de tubérculos de batata em canteiros, vasos e hidroponia. In: CONGRESSO BRASILEIRO DE OLERICULTURA, 45. Resumos...Goiânia: SOB (CD-ROM).

DANIELS J; PEREIRA AS; FORTES GRL. 2000. Verticalização da produção de batata-semente por produtores de agricultura familiar no Rio Grande do Sul. Pelotas: EMBRAPA CLIMA TEMPERADO, 4p. (Comunicado Técnico).

EMBRAPA. 2000. Manual de procedimentos da Embrapa Negócios Tecnológicos para produção e comercialização de batata-semente básica marca Embrapa. Canoinhas: Embrapa SNT, 43p.

FAVORETTO P. 2005. Parâmetros de crescimento e marcha de absorção de nutrientes na produção de minitubérculos de batata cv. Atlantic. Piracicaba: USP - ESALQ. 98p (Tese mestrado).

LUGT C; BODLAENDER KBA.; GOODIJK G. 1964. Observations on the induction of secondgrowth in potato tuber. European Potato Journal 4: 219-227.

MEDEIROS CAB. 2003. Batata semente pré-básica: multiplicação por hidroponia. In: PEREIRA AS, DANIELS J. (eds). O Cultivo da batata na região sul do Brasil. Brasília: Embrapa. p.144-474.

MEDEIROS CAB; ZIEMER AH; DANIELS J; PEREIRAAS. 2002. Produção de sementes prébásicas de batata em sistemas hidropônicos. Horticultura Brasileira 20: 110-114.

MURO JV; GONI JL; LAMSFUS C. 1997. Comparison of hydroponic culture and culture in a peat/sand mixture and the influence of nutrient solution and plant density on seed potato yields. Potato Research 40: 431-438.

PEREIRA JES; MEDEIROS CAB; FORTES GRL; PEREIRA AS; DANIELS J. 2001. Avaliação de dois sistemas hidropônicos para a produção de sementes pré-básicas de batata. In: CONGRESSO BRASILEIRO DE OLERICULTURA, 41. Resumos...São Pedro: SOB (CD-ROM).

RELLOSO JB; PASCUALENA J; RITTER E. 2000. Sistema aeroponico en la producción de patata de siembra de categoría prebase. In: PASCUALENA J; RITTER E. (eds). Libro de Actas del Congreso Iberoamericano de Investigación y Desarrollo en Patata. Vitória: Potato 2000. p.285-297.

RITTER E; ANGULO B; RIGA P; HERRÁN J; RELLOSO J; SAN JOSE M. 2001. Comparison of hydroponic and aeroponic cultivation systems for the production of potato minitubers. Potato Research 44: 127-135.

ROLOT JL; SEUTIN H. 1999. Soilless production of potato minitubers using a hydroponic technique. Potato Research 42: 457-469.

ROLOT JL; SEUTIN H; MICHELANTE D. 2002. Production de minitubercules de pomme de terre par hydroponie: évaluation d'un système conbinant les techniques "NFT" et "Gravel Culture" pour deux types de solution nutritives. Biotechnological Agronomy Society Enviromenty 6: 155-161. 
SOFFER H; BURGER DW. 1998. Effects of dissolved oxygen concentration in aerohydroponics on the formation and growth of adventitious roots. Journal of the American Society for Horticultural Science 113: 218-221.

WAN W; CAO W; TIBBITTS TW. 1994. Tuber initiation in hidroponically grown potatoes by alteration of solution $\mathrm{pH}$. HortScience 29: 621-623.

WHEELER RM; MACKOWIAK JC; SAGER WL; BERRY WL; KNOTT WM; HINKLE CR. 1990. Potato growth and yield using nutrient film technique (NFT). American Journal of Potato Research 67: 177-187.
VERMEER H. 1990. Optimizing potato breeding. The genotypic, environmental, and genotypeenvironmental coefficients of variation for tuber yield and other traits in potato (Solanum tuberosum L.) under different experimental conditions. Euphytica 49: 229-239.
VREUGDENHIL D; STRUIK PC. 1989. An integrated view of the hormonal regulation of tuber formation in potato (Solanum tuberosum). Physiologia Plantarum 75: 525531. 